\title{
Measuring input-specific productivity change based on the principle of least action
}

\section{Juan Aparicio, Magdalena Kapelko, Bernhard Mahlberg \& Jose L. Sainz- Pardo}

Journal of Productivity Analysis

ISSN 0895-562X

J Prod Anal

DOI 10.1007/s11123-016-0488-9

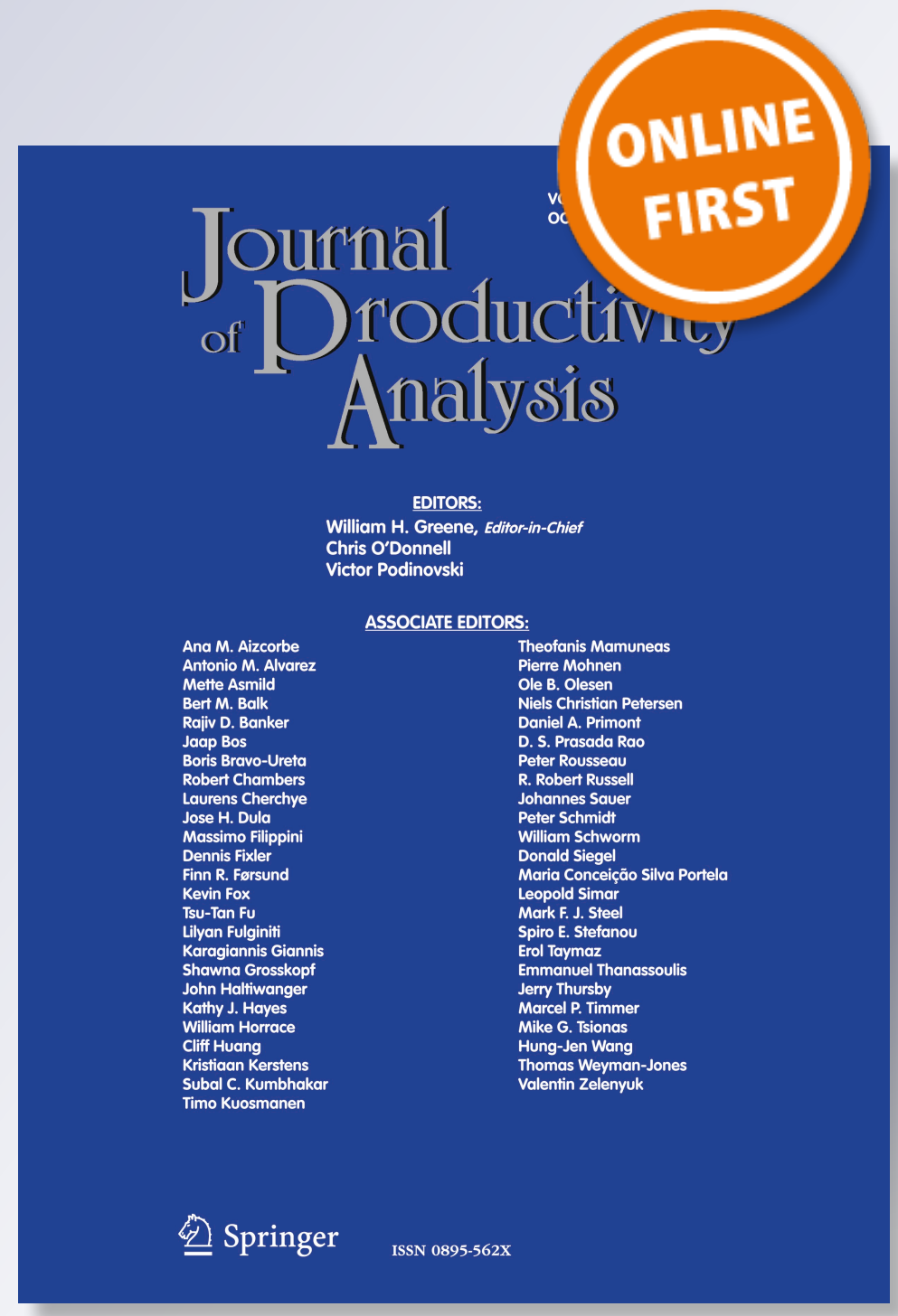

望 Springer 
Your article is protected by copyright and all rights are held exclusively by Springer Science +Business Media New York. This e-offprint is for personal use only and shall not be selfarchived in electronic repositories. If you wish to self-archive your article, please use the accepted manuscript version for posting on your own website. You may further deposit the accepted manuscript version in any repository, provided it is only made publicly available 12 months after official publication or later and provided acknowledgement is given to the original source of publication and a link is inserted to the published article on Springer's website. The link must be accompanied by the following text: "The final publication is available at link.springer.com". 


\title{
Measuring input-specific productivity change based on the principle of least action
}

\author{
Juan Aparicio $\mathbb{( i}^{1} \cdot$ Magdalena Kapelko $\mathbb{D}^{2} \cdot$ Bernhard Mahlberg $\mathbb{i}^{3,4}$ • \\ Jose L. Sainz-Pardo ${ }^{1}$
}

(C) Springer Science+Business Media New York 2016

\begin{abstract}
In for-profit organizations, efficiency and productivity measurement with reference to the potential for input-specific reductions is particularly important and has been the focus of interest in the recent literature. Different approaches can be formulated to measure and decompose input-specific productivity change over time. In this paper, we highlight some problems within existing approaches and propose a new methodology based on the Principle of Least Action. In particular, this model is operationalized in the form of a non-radial Luenberger productivity indicator based on the determination of the least distance to the strongly efficient frontier of the considered production possibility sets, which are estimated by non-parametric techniques based upon Data Envelopment Analysis. In our approach, overall productivity change is the sum of inputspecific productivity changes. Overall productivity change and input-specific changes are broken up into indicators of efficiency change and technical change. This decomposition enables the researcher to quantify the contributions of each production factor to productivity change and its components. In this way, the drivers of productivity development
\end{abstract}

Bernhard Mahlberg

Mahlberg@iwi.ac.at

Bernhard.Mahlberg@wu.ac.at

1 Center of Operations Research, University Miguel Hernandez, Elche (Alicante) 03202, Spain

2 Institute of Applied Mathematics, Department of Logistics, Wroclaw University of Economics, Wroclaw, Poland

3 Institute for Industrial Research, Mittersteig 10/4, Vienna 1050, Austria

4 Vienna University of Economics and Business, Welthandelsplatz 1, Vienna 1020, Austria are revealed. For illustration purposes the new approach is applied to a recent dataset of Polish dairy processing firms.

Keywords Data envelopment analysis $\cdot$ Weighted additive model $\cdot$ Closest targets $\cdot$ Input-specific productivity change

JEL codes $\mathrm{C} 43 \cdot \mathrm{C} 61 \cdot \mathrm{Q} 12$

\section{Introduction}

In for-profit organizations, productivity and efficiency analysis over time can provide important insights into the evolution of firms' performance and their degree of competitiveness, and can therefore support better decision making in companies and the development of firms' strategies and policy instruments. The particular case of this analysis concerns the productivity and efficiency measurement with reference to the potential for input-specific reductions. The need to understand the efficiency and productivity change of firms in terms of their individual inputs employed is clear. For example, technological growth facilitates the substitution of relatively scarce and expensive inputs by relatively abundant and cheap inputs, therefore having a differential effect on input efficiency and productivity. Such analyses are valuable for effective resource allocation and obtaining insights into the scope for input use improvement.

The conventional approach in Data Envelopment Analysis (DEA) literature is to use productivity growth measures for all inputs simultaneously. Only recently, the measurement of productivity change over time with regard to the specific inputs has received an increasing interest in DEA research. Different approaches have been developed 
to measure and decompose input-specific productivity change over time. These can be broadly classified into two main groups: Malmquist-type input-specific productivity growth measures that are multiplicative in nature (Oude Lansink and Ondersteijn 2006; Mahlberg et al. 2011) and Luenberger-based indicators that have an additive structure (Mahlberg and Sahoo 2011; Chang et al. 2012; Skevas and Oude Lansink 2014; Mahlberg and Luptacik 2014; Kapelko et al. 2015a; Luptacik and Mahlberg 2016). Compared to the studies on input-specific productivity and efficiency change over time, the analysis of input-specific efficiency at a specific point in time is a subject of a longer tradition in DEA literature (see, e.g., Färe et al. 1994; Oude Lansink and Silva 2003; D'Haese et al. 2009).

In spite of the variety of methods being developed to measure input-specific productivity growth, as we will show in this paper, all of them are directly or indirectly founded on the input-oriented weighted additive model that was first introduced by Lovell and Pastor (1995). Moreover, several problems can be highlighted with existing input-specific productivity models, which motivate the need to develop a new method. One important shortcoming of existing approaches is related to the determination of the targets by the furthest efficient projection to the assessed decision making unit (DMU). Hence, the targets created by these approaches are not easily achievable by firms. Other problems refer to the cross-period evaluations in the estimation of productivity change in which the projections onto the weekly efficient frontier are undertaken and the inconsistency occurs when the least distance to the frontier is determined for units that remain outside the technology and the furthest distance for units located within the technology. In this paper we propose a new method of the measurement of input-specific productivity change over time in the DEA framework that overcomes the disadvantages of existing approaches. The proposed method is based on the Principle of Least Action (Aparicio et al. 2014) and is related to the notion of least distance and the determination of closest efficient targets (Briec 1998; Coelli 1998; Joro et al. 1998; Gonzalez and Alvarez 2001; Portela et al. 2003; Aparicio et al. 2007; Aparicio and Pastor 2013, 2014; Fukuyama et al. 2014a, b). The general idea behind the Principle of Least Action in efficiency analysis is that by assuming closest targets inefficient DMUs can achieve technical efficiency with a minimum amount of technical effort as reflected by the change in inputs and outputs. Hence, it is particularly useful when it is important for the DMU analyzed to achieve technical efficiency as soon as possible. In addition, the method developed in this paper always projects to the strongly efficient frontier, hence allowing the Pareto-efficiency (or Koopmans (1951) efficiency) to be reached. The determination of Pareto-efficiency guarantees that the benchmarked firms are compared with the best performing firms. To the best of our knowledge, this article is the first to develop and apply an input-specific productivity change model derived from the estimation of the shortest distance to the strongly efficient frontier. Our model is operationalized in the form of an input-specific Luenberger productivity change indicator. In our approach, input-specific productivity changes are summed up to form an overall productivity change. Then, both input-specific and overall productivity changes are decomposed into indicators of efficiency change and technical change, which allow us to discuss the sources of individual and overall productivity changes.

As the empirical illustration of our proposed methodology to measure input-specific productivity change, we use a sample of dairy processing firms that operated in Poland between 2003 and 2012. In our empirical application we focus on one output (revenues), and three inputs (material costs, employee costs and fixed assets) and their contributions towards overall productivity change.

The remainder of the paper proceeds as follows. Section 2 summarizes the existing approaches to the measurement of input-specific productivity change pointing out some of their drawbacks. Section 3 introduces our method to measure productivity change and its components with regard to specific inputs. Section 4 presents the empirical illustration of the method developed, including the description of the data set and discussion of the results. Finally, Section 5 provides concluding comments.

\section{Notation and review of the literature}

In this section, we briefly review existing approaches where the issue of measuring and decomposing input-specific productivity change has been analyzed. Nevertheless, we first need to introduce some notations.

Consider, as usual, that we have observed $n$ decision making units (DMUs) that use $m$ inputs to produce $q$ outputs. These are denoted by $\left(x_{j}, y_{j}\right), j=1, \ldots, n$. It is assumed that $x_{j}=\left(x_{1 j}, \ldots, x_{m j}\right) \in R_{++}^{m}, j=1, \ldots, n$, and $y_{j}=\left(y_{1 j}, \ldots, y_{q j}\right) \in R_{+}^{q}, j=1, \ldots, n$. The relative efficiency of each $\mathrm{DMU}_{0}$ in the sample is assessed with reference to the so-called production possibility set $T=\{(x, y) \mid x$ can produce $y\}$, which can be empirically constructed from $n$ observations by assuming several postulates (see Banker et al. 1984). If, in particular, Constant Returns to Scale (CRS) is assumed, then $T$ can be characterized as follows:

$$
T=\left\{(x, y) \in R_{+}^{m+s} \mid x \geq \sum_{j=1}^{n} \lambda_{j} x_{j}, \mathrm{y} \leq \sum_{j=1}^{n} \lambda_{j} y_{j}, \lambda_{j} \geq 0, \mathrm{j}=1, \ldots, \mathrm{n}\right\} .
$$


The weakly efficient frontier of $T$ is defined as $\partial^{w}(T):=\{(x, y) \in T: \hat{x}<x, \hat{y}>y \Rightarrow(\hat{x}, \hat{y}) \notin T\}$, while the strongly efficient frontier is defined as $\partial^{s}(T):=\{(x, y) \in$ $T: \hat{x} \leq x, \hat{y} \geq y,(\hat{x}, \hat{y}) \neq(x, y) \Rightarrow(\hat{x}, \hat{y}) \notin T\}$. In words, $\partial^{s}(T)$ is the set of all the non-dominated points of $T$.

Regarding the measure of technical efficiency, we may find two different approaches to assess the technical performance of DMUs in DEA literature. On the one hand, several measures compare the actual performance of each evaluated DMU, $\left(x^{\prime}, y^{\prime}\right)$, with respect to the points belonging to the weakly efficient frontier (e.g., radial measures (Charnes et al. 1978; Banker et al. 1984) and directional distance functions (Chambers et al. 1996, 1998)). In contrast, some measures compare each unit with respect to the strongly efficient frontier (e.g., the Range Adjusted Measure (Cooper et al. 1999) and the Enhanced Russell Graph (Pastor et al. 1999; Tone 2001)). In this paper, we follow this second line of research, measuring the distance from a point to the frontier of a technology by resorting to the strongly efficient frontier instead of the weakly efficient frontier.

Another interesting issue, when efficiency is to be measured, is orientation. In most empirical applications, technical efficiency is measured either in input- or in outputorientation, and it has to do with the variables that are most easily controlled and changed by the DMU. The choice between the two also depends on the interests and objectives of the decision maker. This paper focuses on inputorientation since we are interested in estimating inputspecific productivity changes. So, the new approach will be useful in contexts where a consistent behavior with respect to input-orientation makes sense. In order to implement this approach, introducing the input requirement set is useful. In this sense, for each output vector $y$, let $L(y)$ be the set of inputs that may produce $y$. Formally, $L(y)=\{x:(x, y) \in T\}$. In the same manner as for $T$, we can define the weakly efficient frontier and the strongly efficient frontier in the inputoriented framework.

$\partial^{w}(L(y)):=\{x \in L(y): \hat{x}<x \Rightarrow \hat{x} \notin L(y)\}$.

$\partial^{s}(L(y)):=\{x \in L(y): \hat{x} \leq x, \hat{x} \neq x \Rightarrow \hat{x} \notin L(y)\}$.

Now, we turn to the definition of the input-oriented weighted additive model. Weighted additive models (WA) were firstly introduced by Lovell and Pastor (1995). In input and output oriented versions of the WA models, the objective function is restricted in a way that only input or output slacks are maximized. In the case of the inputoriented weighted additive model, the corresponding measure is calculated by the following optimization program.

$$
\begin{aligned}
& W A_{I}\left(x_{0}, y_{0}\right)=\operatorname{Max} \sum_{i=1}^{m} w_{i} s_{i}^{-} \\
& \qquad \begin{array}{l}
\text { s.t. } \\
\sum_{j=1}^{n} \lambda_{j} x_{i j}+s_{i}^{-} \leq x_{i 0}, \quad i=1, \ldots, m \\
-\sum_{j=1}^{n} \lambda_{j} y_{r j} \leq-y_{r 0}, \quad r=1, \ldots, q, \\
s_{i}^{-} \geq 0, \quad i=1, \ldots, m \\
\lambda_{j} \geq 0, \quad j=1, \ldots, n
\end{array}
\end{aligned}
$$

where $\left(w_{1}, \ldots, w_{m}\right) \in R_{++}^{m}$ are weights representing the relative importance of unit inputs, $\left(\lambda_{1}, \ldots, \lambda_{n}\right)$ the usual intensity variables and $\left(s_{1}^{-}, \ldots, s_{m}^{-}\right)$the input slacks.

Proposition 1 Let $x_{0} \in L\left(y_{0}\right)$ and let $\left(s^{-*}, \lambda^{*}\right)$ be an optimal solution of (4), then $\sum_{j=1}^{n} \lambda_{j}^{*} x_{i j}+s_{i}^{-*}=x_{i 0}, i=1, \ldots, m$.

\section{Proof Trivial.}

In DEA, the technical inefficiency assessment of each observed unit $\left(x_{0}, y_{0}\right)$ is obtained as the result of its comparison with a dominating projection point on the frontier of the input requirement set. The coordinates of this projection will be the targets for $\left(x_{0}, y_{0}\right)$. Regarding the input-oriented weighted additive model, given an optimal solution of (4), $\left(s^{-*}, \lambda^{*}\right)$, the targets are defined as $x_{i 0}^{*}=x_{i 0}-s_{i}^{-*}, \quad i=1, \ldots, m$, which coincide with $\sum_{j=1}^{n} \lambda_{j}^{*} x_{i j}$ for $i=1, \ldots, m$ by Proposition 1 . Next, we show a property related to the targets derived from the input-oriented weighted additive model. The following proposition establishes that the targets generated from (4) are always Pareto-Koopmans efficient points of $L\left(y_{0}\right)$.

Proposition 2 Let $x_{0} \in L\left(y_{0}\right)$ and let $\left(s^{-*}, \lambda^{*}\right)$ be an optimal solution of (4). Then $\left(x_{10}^{*}, \ldots, x_{m 0}^{*}\right) \in \partial^{s}\left(L\left(y_{0}\right)\right)$.

Proof See Lovell and Pastor (1995).

As a direct implication of Propositions 1 and 2, the inputoriented weighted additive model, specifically expression (4), may be equivalently rewritten through the following 'compact' formulation:

$$
\begin{gathered}
W A_{I}\left(x_{0}, y_{0}\right)=\operatorname{Max}\left\{\sum_{i=1}^{m} w_{i} s_{i}^{-}:\left(x_{10}-s_{1}^{-}, \ldots, x_{m 0}-s_{m}^{-}\right) \in \partial^{s}\right. \\
\left.\left(L\left(y_{0}\right)\right), s_{i}^{-} \geq 0, i=1, \ldots, m\right\}
\end{gathered}
$$

Before going on, it is interesting to note that probably the main property that characterizes the weighted additive models is the ability of detecting Pareto-Koopmans efficiency, in this case in the input space, something that does not happen with radial measures or directional distance functions. 
Proposition $3 x_{0} \in \partial^{s}\left(L\left(y_{0}\right)\right) \Leftrightarrow W A_{I}\left(x_{0}, y_{0}\right)=0$.

Proof See Lovell and Pastor (1995).

Turning to efficiency and productivity measurement with reference to the potential for input-specific reductions, different approaches that can be found to measure and decompose input-specific productivity change over time, resort to a version of the input-oriented weighted additive model, although the different authors invoke the name of other measures ${ }^{1}$. In particular, Oude Lansink and Ondersteijn (2006, p. 127) resorted to the Russell input measure (Färe et al. 1985) in the context of two inputs (energy and other inputs) and one output. Applying the well-known change of variables $s_{i}^{-}=x_{i 0}-\theta_{i} x_{i 0}, i=1,2$, we get that the Russell input measure coincides with one minus the inefficiency of the inputoriented weighted additive model with specific weights $w_{i}=1 /$ $2 x_{i 0}, i=1,2$. It is also worth mentioning that in the Oude Lansink and Ondersteijn approach a Malmquist productivity index was utilized to estimate productivity change.

On the other hand, Mahlberg and Sahoo (2011) resorted to an input-oriented version of the directional slacks-based measure of inefficiency by Fukuyama and Weber (2009), also called directional Russell measure of technical inefficiency, in order to analyze the eco-productivity performance behavior of 22 OECD countries during the period 1995-2004. However, Pastor and Aparicio (2010) had already shown that the directional slacks-based measure is equivalent to a weighted additive measure. Therefore, once more model (4) applies with particular weights $w_{i}=1 / m x_{i 0}$, $i=1, \ldots, m$. Additionally, in the paper of Mahlberg and Sahoo (2011), a Luenberger indicator and its corresponding input-specific components were developed.

Later, Chang et al. (2012) used the following model for disaggregating the sources of bank productivity growth in China.

$$
\begin{aligned}
& \operatorname{Max} \frac{1}{m} \sum_{i=1}^{m} \beta_{i} \\
& \text { s.t. } \\
& \qquad \sum_{j=1}^{n} \lambda_{j} x_{i j} \leq x_{i 0}\left(1-\beta_{i}\right), \quad i=1, \ldots, m \\
& -\sum_{j=1}^{n} \lambda_{j} y_{r j} \leq-y_{r 0}, \quad r=1, \ldots, q \\
& \beta_{i} \geq 0, \quad i=1, \ldots, m \\
& \lambda_{j} \geq 0, \quad j=1, \ldots, n .
\end{aligned}
$$

where $\beta_{i}, i=1, \ldots, m$, represents the proportion in which each input must be reduced to reach the frontier of the production possibility set.

\footnotetext{
$\overline{1}$ Input-oriented radial models search for equiproportional reductions in all the inputs. In this way, these models are not prepared to allow the decomposition of the "global" productivity change into the different effects of inputs on this change. This is probably the reason why the previous literature devoted to input-specific productivity did not resort to radial models to deal with input-specific productivity change.
}

Considering the change of variables $s_{i}^{-}=\beta_{i} x_{i 0}, i=1, \ldots$, $m$, we get that model (6) is equivalent to an input-oriented weighted additive model with weights $w_{i}=1 / m x_{i 0}, i=1, \ldots$, $m$. Chang et al. (2012) also utilized a Luenberger indicator to measure productivity change over time as Mahlberg and Sahoo (2011).

Additionally, the works by Skevas and Oude Lansink (2014) and Kapelko et al. (2015a) used a similar model to (6), with the difference in the objective function (the usage of an average versus a total) and in the presentation of the constraint for inputs. The main difference between Skevas and Oude Lansink (2014) and Kapelko et al. (2015a) is that Skevas and Oude Lansink (2014) assumed weak disposability of some inputs and outputs, and in Kapelko et al. (2015a) the strong disposability assumption was maintained. In these two last papers, $g_{i}=x_{i 0}$ for all $i=1, \ldots, m$ in their corresponding empirical applications.

As we have just shown, the approaches devoted to decompose productivity change into its input-specific sources were all based on an input-oriented version of the weighted additive model. It is worth mentioning that most of them additionally resorted to the Luenberger indicator and an additive decomposition instead of using a Malmquist index and a multiplicative approach.

The foregoing approaches have certain disadvantages in a practical context which the technical inefficiency measure we put forward in this paper overcomes. The key drawbacks of the traditional input-oriented additive model applied to this framework are as follows.

\subsection{Furthest targets}

Model (4) determines the furthest targets from the assessed unit $\left(x_{0}, y_{0}\right)$ to the strongly efficient frontier of $L\left(y_{0}\right)$, since the objective function maximizes the (weighted) sum of slacks $\sum_{i=1}^{m} w_{i} s_{i}^{-}$and, at the optimum, $s_{i}^{-*}=x_{i 0}-\sum_{j=1}^{n} \lambda_{j}^{*} x_{i j}=$ $x_{i 0}-x_{i 0}^{*} \geq 0$ for all $i=1, \ldots, m$ by Proposition 1 . In contrast, the problem of deriving the closest projection has been one of the relevant issues in recent DEA literature (see, e.g., Briec 1998; Joro et al. 1998; Coelli 1998; Gonzalez and Alvarez 2001; Portela et al. 2003; Aparicio et al. 2007; Cook and Seiford 2009; Ando et al. 2012; Aparicio and Pastor 2013; Aparicio et al. 2014; Fukuyama et al. 2014a, b, among others).

\subsection{Different philosophies are applied outside and within the technology}

For the estimation of productivity change, in the case of the cross-period evaluation when a unit $\left(x_{0}^{t+1}, y_{0}^{t+1}\right)$ under assessment is outside the technology set of period t models with the non-negativity constraints for slacks $s_{i}^{-} \geq 0, i=1$, ..., $m$, (e.g. (4)) yield no feasible solutions (see Mahlberg and Sahoo 2011). So, it is necessary to change the non- 
negativity constraints by $s_{i}^{-} \leq 0, i=1, \ldots, m$, as it is shown in the following model.

$$
\begin{aligned}
& W A_{I}^{t}\left(x_{0}^{t+1}, y_{0}^{t+1}\right)=\operatorname{Max} \sum_{i=1}^{m} w_{i} s_{i}^{-} \\
& \text {s.t. } \\
& \qquad \begin{array}{l}
\sum_{j=1}^{n} \lambda_{j} x_{i j}^{t}+s_{i}^{-} \leq x_{i 0}^{t+1}, \quad i=1, \ldots, m \\
-\sum_{j=1}^{n} \lambda_{j} y_{r j}^{t} \leq-y_{r 0}^{t+1}, \quad r=1, \ldots, q \\
s_{i}^{-} \leq 0, \quad i=1, \ldots, m \\
\lambda_{j} \geq 0, \quad j=1, \ldots, n .
\end{array}
\end{aligned}
$$

Note that (7) is equivalent to $-\operatorname{Min}\left[-\sum_{i=1}^{m} w_{i} s_{i}^{-}\right]$subject to the same constraints as in (7). So, finally, model (7) can be equivalently calculated by (8).

$$
\begin{aligned}
& W A: I^{t}\left(x_{0}^{t+1}, y_{0}^{t+1}\right)=-\operatorname{Min} \sum_{i=1}^{m} w_{i} h_{i}^{-} \\
& \text {s.t. } \\
& \qquad \begin{aligned}
\sum_{j=1}^{n} \lambda_{j} x_{i j}^{t}-h_{i}^{-} \leq x_{i 0}^{t+1}, \quad i=1, \ldots, m \\
-\sum_{j=1}^{n} \lambda_{j} y_{r j}^{t} \leq-y_{r 0}^{t+1}, \quad r=1, \ldots, q \\
h_{i}^{-} \geq 0, \quad i=1, \ldots, m \\
\lambda_{j} \geq 0, \quad j=1, \ldots, n,
\end{aligned}
\end{aligned}
$$

where $h_{i}^{-}=-s_{i}^{-} \geq 0, i=1, \ldots, m$. Model (8) minimizes $\sum_{i=1}^{m} w_{i} h_{i}^{-}$with $h_{i}^{-} \geq 0, i=1, \ldots, m$, therefore searching for slacks as small as possible and yielding the closest targets $x_{i 0}^{t+1 *}=x_{i 0}^{t+1}+h_{i}^{-}, i=1, \ldots, m$, for $x_{0}^{t+1}$. Therefore, the usual measures for estimating input-specific productivity change resort to the determination of the least distance to the frontier of the reference technology for units that remain outside and the estimation of furthest targets in the case of units located within technology, something that may be seen as an inconsistency.

\subsection{Projections onto the weakly efficient frontier}

In Fig. 1, we graphically illustrate both the usual geometry of the input requirement set and the subsets of its frontier. The bold solid line corresponds to the strongly efficient frontier, consisting of two segments, $\mathrm{AB}$ and $\mathrm{BC}$. The weakly efficient frontier corresponds to the union between the strongly efficient frontier and the dashed lines that appear in the figure.

As we mentioned before, the most characteristic property of the input-oriented weighted additive model is the possibility of signaling Pareto-Koopmans efficiency in the input space, in contrast to the input-oriented radial model or the

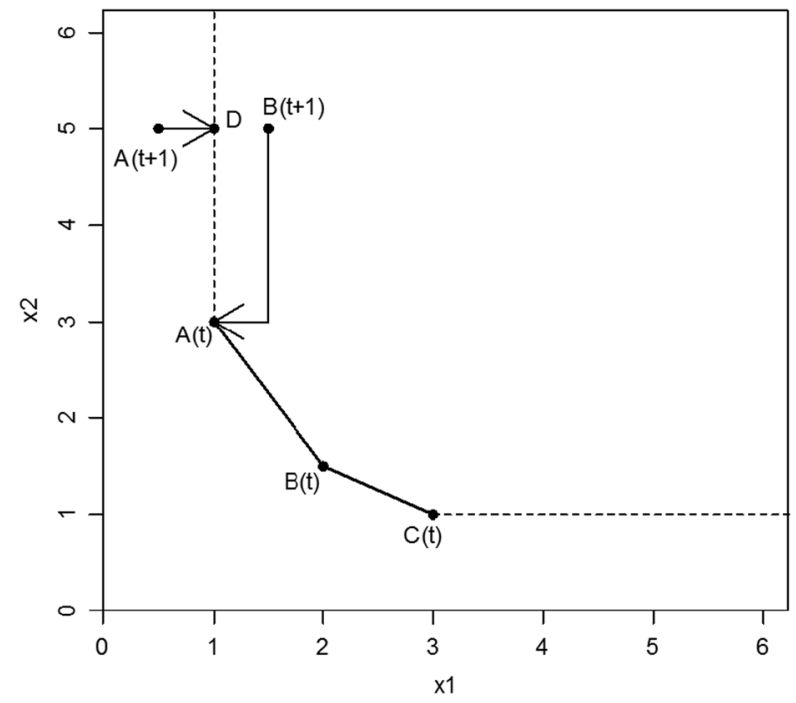

Fig. 1 Example for the input-oriented weighted additive model not reaching strongly efficient frontier for cross-period evaluations

directional input distance function. However, when a model of these characteristics is utilized in order to estimate productivity change, a problem arises for the cross-period evaluations. In these situations, it can be shown that the subset of the corresponding frontier used to calculate the distance between the assessed unit and the technology no longer matches the strongly efficient frontier $\partial^{s}\left(L\left(y_{0}\right)\right)$. We will go on to illustrate this with a graphical example (see Fig. 1). For this example, we assume that $w_{i}=1 / m x_{i 0}, i=1, \ldots, m$. In Fig. 1, if we evaluate unit A observed in period $t+1$, denoted as $\mathrm{A}(\mathrm{t}+1)$, with respect to the technology in $\mathrm{t}$ we have to solve model (8), obtaining $h_{1}^{-*}=0.5$ and $h_{2}^{-*}=0$. These slacks yield the targets $0.5+h_{1}^{-*}=0.5+0.5=1$ for the first input and $5+h_{2}^{-*}=5+0=5$ for the second input, matching the components of (non-observed) point $\mathrm{D}$ in the figure. As can be noted, point $\mathrm{D}$ does not belong to the strongly efficient frontier in period $t$ since it is dominated by unit $A(t)$ in the sense of Pareto. This is an important problem in contexts where slacks are viewed as significant in revealing the inefficiency behavior of firms, since the distance to the strongly efficient frontier could be incorrectly estimated.

\section{A new version of the input-oriented weighted additive model based on the principle of least action}

In this section, we introduce a new version of the traditional input-oriented weighted additive measure in order to avoid some drawbacks, highlighted above, of the existing approaches to estimate input-specific productivity changes. To do that, we base our model on the Principle of Least Action (Aparicio et al. 2014), which is intimately related to the notion of least distance. The model also allows for the 
determination of strongly efficient targets. Following the literature, the new model will use $w_{i}=1 / m x_{i 0}, i=1, \ldots, m$ as input weights, being $x_{i 0}$ the input $i$ of the assessed unit. Additionally, we will develop all the necessary theory under the assumption of using one output and several inputs (e.g. operating revenues vs. capital, labor and materials). In fact, this was the framework adopted by most published applications, see, e.g., Oude Lansink and Ondersteijn (2006), Mahlberg and Sahoo $(2011)^{2}$, Skevas and Oude Lansink (2014) and Kapelko et al. (2015a).

Now, we turn to the presentation of main results and models. First of all, let us rewrite model (4) under the hypothesis of $q=1$ (one output) and $w_{i}=1 / m x_{i 0}, \forall i=1, \ldots$, $m$. This will be model (9). Moreover, let us show the dual linear program of (9). By duality, we know that the optimal values of both models are the same.

$$
\begin{aligned}
W A_{I}\left(x_{0}, y_{0}\right)= & \operatorname{Max} \sum_{i=1}^{m} \frac{s_{i}^{-}}{m x_{i 0}} \\
& \text { s.t. } \\
& \sum_{j=1}^{n} \lambda_{j} x_{i j}+s_{i}^{-} \leq x_{i 0}, \quad i=1, \ldots, m \\
& -\sum_{j=1}^{n} \lambda_{j} y_{j} \leq-y_{0}, \\
& s_{i}^{-} \geq 0, \quad i=1, \ldots, m \\
& \lambda_{j} \geq 0, \quad j=1, \ldots, n, \\
\text { WA }\left(x_{0}, y_{0}\right)= & \operatorname{Min} \sum_{i=1}^{m} \nu_{i} x_{i 0}-\mu y_{0} \\
\text { s.t. } \quad & \\
& \sum_{i=1}^{m} \nu_{i} x_{i j}-\mu y_{j} \geq 0, \quad j=1, \ldots, n \\
& \nu_{i} \geq \frac{1}{m x_{i 0}}, \quad i=1, \ldots, m \\
& \nu_{i} \geq 0, \quad i=1, \ldots, m \\
& \mu \geq 0,
\end{aligned}
$$

where $\nu_{i}, i=1, \ldots, m$, and $\mu$ are the multipliers of the model.

Before going on, we need to prove that for any optimal solution of (9), we have that the inequality constraint $-\sum_{j=1}^{n} \lambda_{j} y_{j} \leq-y_{0}$ is binding.

Proposition 4 Let $y_{0}>0$ and let $\left(s^{-*}, \lambda^{*}\right)$ be an optimal solution of (9), then $-\sum_{j=1}^{n} \lambda_{j}^{*} y_{j}=-y_{0}$.

Proof Let us assume that $-\sum_{j=1}^{n} \lambda_{j}^{*} y_{j}<-y_{0}$. Let us define $y_{0}^{*}:=\sum_{j=1}^{n} \lambda_{j}^{*} y_{j}$. In this way, $y_{0}^{*}>y_{0} \Leftrightarrow y_{0} / y_{0}^{*}<1$. Under the assumption of CRS, see expression (1), $\frac{y_{0}}{y_{0}^{*}}\left(x_{0}^{*}, y_{0}^{*}\right) \in T$ since $\left(x_{0}^{*}, y_{0}^{*}\right) \in T$, where $x_{0}^{*}=\left(x_{10}^{*}, \ldots, x_{m 0}^{*}\right)$ with

\footnotetext{
2 These authors really use one good output and one bad output. Nevertheless, they mathematically deal with the bad output as an input in their approach.
}

$x_{i 0}^{*}=x_{i 0}-s_{i}^{-*}=\sum_{j=1}^{n} \lambda_{j}^{*} x_{i j}, i=1, \ldots, m$, by Proposition 1. By the definition of $L(y)$, we have that $\frac{y_{0}}{y_{y}^{*}} x_{0}^{*} \in L\left(y_{0}\right)$. On the other hand, if $x_{i 0}^{*} \neq 0$ then $\frac{y_{0}}{y_{0}^{*}} x_{i 0}^{*}<x_{i 0}^{*}$ and, otherwise, $\frac{y_{0}}{y_{0}^{*}} x_{i 0}^{*}=x_{i 0}^{*}$. Nevertheless, $\exists i^{\prime}=1, \ldots, m$ such that $x_{i^{\prime} 0}^{*} \neq 0$. If not, $\lambda_{j}^{*}=0$ for all $j=1, \ldots, n$ since we assumed that $x_{i j}>0$, $\forall i, j$. And then $y_{0}^{*}=\sum_{j=1}^{n} \lambda_{j}^{*} y_{j}=0$. However, $y_{0}^{*}>y_{0}>0$ by hypothesis. In this manner, $x_{0}^{*}$ is strictly dominated by $\frac{y_{0}}{y_{0}^{*}} x_{0}^{*}$, which is a contradiction by Proposition 2 .

Next we establish the main result of the paper. In particular, Theorem 1 characterizes the points belonging to the strongly efficient frontier of $L(y)$.

Theorem 1 Let $y_{0}>0$. The strongly efficient frontier of $L\left(y_{0}\right)$ can be characterized as follows.

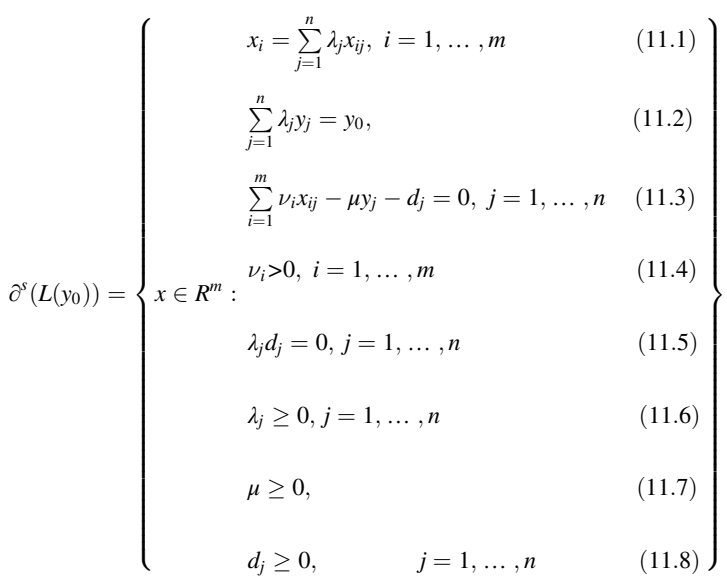

Proof (i) Let $(\bar{\lambda}, \bar{\nu}, \bar{\mu}, \bar{d})$ be a vector that satisfies constraints 11.2-11.8. From this solution, it is possible to generate $\bar{x}$ as $\bar{x}_{i}:=\sum_{j=1}^{n} \bar{\lambda}_{j} x_{i j}$ and $\bar{y}$ as $\bar{y}:=\sum_{j=1}^{n} \bar{\lambda}_{j} y_{j}=y_{0}$, where the last equality is true by (11.2). Let us note that, by (1), $(\bar{x}, \bar{y}) \in T$ and, consequently, $\bar{x} \in L\left(y_{0}\right)$. Let us now assume that $\exists x^{\prime} \in L\left(y_{0}\right)$ such that $x^{\prime} \leq \bar{x}$ with $x^{\prime} \neq \bar{x}$. We want to arrive at a contradiction. By (11.3) and (11.8), we have that $\sum_{i=1}^{m} \bar{\nu}_{i} x_{i j}-\bar{\mu} y_{j} \geq 0$ for all $j=1, \ldots, n$. And, by the definition of $T$ in (1), we know that $\sum_{i=1}^{m} \bar{\nu}_{i} x_{i}-\bar{\mu} y \geq 0$ for all $(x, y) \in T$. This implies that $\sum_{i=1}^{m} \bar{\nu}_{i} x_{i}-\bar{\mu} y_{0} \geq 0$ for all $\left(x, y_{0}\right) \in T$. In this way, $\sum_{i=1}^{m} \bar{\nu}_{i} x_{i}^{\prime}-\bar{\mu} y_{0} \geq 0$ since $\left(x^{\prime}, y_{0}\right) \in T$ because $x^{\prime} \in L\left(y_{0}\right)$. On the other hand, $\sum_{i=1}^{m} \bar{\nu}_{i} \bar{x}_{i}-\bar{\mu} y_{0}=$ $\sum_{i=1}^{m} \bar{\nu}_{i} \bar{x}_{i}-\bar{\mu} \bar{y}=\sum_{i=1}^{m} \bar{\nu}_{i}\left(\sum_{j=1}^{n} \bar{\lambda}_{j} x_{i j}\right)-\bar{\mu}\left(\sum_{j=1}^{n} \bar{\lambda}_{j} y_{j}\right)=$

$\sum_{j=1}^{n} \bar{\lambda}_{j} \underbrace{\left.\sum_{i=1}^{m} \bar{\nu}_{i} x_{i j}-\bar{\mu} y_{j}\right)}_{\left.=\bar{d}_{j} \text { by }(11.3)\right]}=\sum_{j=1}^{n} \bar{\lambda}_{j} \bar{d}_{j}=0 \quad$ by

Finally, we have that $\sum_{i=1}^{m} \bar{\nu}_{i} x_{i}^{\prime}-\bar{\mu} y_{0}<\sum_{i=1}^{m} \bar{\nu}_{i} \bar{x}_{i}-\bar{\mu} y_{0}=$ 0 since $\nu_{i}>0$ (11.4) and $x^{\prime} \leq \bar{x}$ with $x^{\prime} \neq \bar{x}$. However, we proved that, on the one hand, $\sum_{i=1}^{m} \bar{\nu}_{i} x_{i}^{\prime}-\bar{\mu} y_{0} \geq 0$ and, on the other hand, $\sum_{i=1}^{m} \bar{\nu}_{i} \bar{x}_{i}-\bar{\mu} y_{0}<0$. This is the contradiction that we were seeking. Therefore, $\bar{x} \in \partial^{s}\left(L\left(y_{0}\right)\right)$. 
(ii) Let $\bar{x} \in \partial^{s}\left(L\left(y_{0}\right)\right)$ with $y_{0}>0$. Then $\bar{x} \in R_{++}^{m}$ by (1), the definition of $L\left(y_{0}\right), x_{i j}>0, \forall i, j$ and $y_{j}>0, \forall j$. Then we can solve (9) for $x_{0}=\bar{x}$ and, by Proposition 3 , we know that $W A_{I}\left(\bar{x}, y_{0}\right)=0$. Therefore, an optimal solution $\left(\bar{s}^{-}, \bar{\lambda}\right)$ with $\bar{s}^{-}=0$ for (9) exists that satisfies, in particular, the constraints $\quad \sum_{j=1}^{n} \bar{\lambda}_{j} x_{i j}+\bar{s}_{i}^{-} \leq \bar{x}_{i}, \quad i=1, \ldots, m, \quad$ and $-\sum_{j=1}^{n} \bar{\lambda}_{j} y_{j} \leq-y_{0}$. By Proposition 1 and $\bar{s}^{-}=0$, we have that $\bar{x}_{i}=\sum_{j=1}^{n} \bar{\lambda}_{j} x_{i j}[(11.1)]$. Moreover, $\bar{\lambda}_{j} \geq 0, \forall j[(11.6)]$. Additionally, by Proposition $4, \sum_{j=1}^{n} \bar{\lambda}_{j} y_{j}=y_{0}[(11.2)]$. By duality, there exists an optimal solution for $(10)(\bar{\nu}, \bar{\mu}) \in$ $R_{+}^{m} \times R_{+}[(11.7)]$ such that $\sum_{i=1}^{m} \bar{\nu}_{i} x_{i j}-\bar{\mu} y_{j} \geq 0, j=1, \ldots, n$, and $\quad \bar{\nu}_{i} \geq 1 / m x_{i 0}, \quad i=1, \ldots, m \quad$ [(11.4)]. Defining $\bar{d}_{j}:=\sum_{i=1}^{m} \bar{\nu}_{i} x_{i j}-\bar{\mu} y_{j} \geq 0, j=1, \ldots, n,(11.3)$ and (11.8)] are satisfied. Finally, regarding (11.5), by the Complementarity Theorem in Linear Programming we have that $\bar{\lambda}_{j} \bar{d}_{j}=$ $0, j=1, \ldots, n$, i.e. (11.5) holds. Therefore, all the constraints in (11) are satisfied.

Once the strongly efficient frontier of the input requirement set has been characterized, the introduction of the new version of the input-oriented weighted additive model is possible. It will be based on the Principle of Least Action (PLA). Additionally, we wish to slightly change the notation used in order to accommodate the possibility of crossevaluation. In this sense, the compact format of the new measure will be as follows.

$$
\begin{aligned}
& W A_{I, t}^{P L A}\left(x_{0}^{t+1}, y_{0}^{t+1}\right)= \\
& \quad \operatorname{Min}\left\{\sum_{i=1}^{m} \frac{\mid s_{x}^{-1}}{m x_{0}^{+t}}:\left(x_{10}^{x^{+1}}-s_{1}^{-}, \ldots, x_{m 0}^{t+1}-s_{m}^{-}\right) \in \widehat{o}^{s}\left(L^{t}\left(y_{0}^{t+1}\right)\right)\right\} .
\end{aligned}
$$

If we compare (12) vs. (5), some significant differences can be found. First, "Max" has been substituted by 'Min'. Second, the slacks are free variables in (12) and non-negative in (5). Third, the objective function uses the absolute value function to aggregate slacks. Obviously, $W A_{I}^{P L A}\left(x_{0}, y_{0}\right) \geq 0$, being equal to zero if and only if $x_{0} \in \partial^{s}\left(L\left(y_{0}\right)\right)$.

It is worth mentioning that our approach does not suffer from infeasibilities since it is based on calculating a mathematical distance (a weighted $\ell_{1}$ distance) to the strongly efficient frontier (a non-empty set). Therefore, our model always reaches a feasible solution in contrast to the more usual approaches: radial and directional models (Briec and Kerstens 2009).

Nevertheless, (12) is not a standard mathematical program, making its implementation difficult in practice. In this sense, the first step to write an equivalent standard "linear" program consists of applying Theorem 1. Additionally, and before applying this result, note that constraint (11.5), $\lambda_{j} d_{j}=0$ for all $j=1, \ldots, n$, can be rewritten as $d_{j} \leq M b_{j}$, $j=1, \ldots, n, \quad \lambda_{j} \leq M\left(1-b_{j}\right), \quad j=1, \ldots, n, \quad$ and $\quad b_{j} \in\{0,1\}$, $j=1, \ldots, n$, with $M$ being a large enough positive number (see, e.g., Aparicio et al. 2007). Moreover, following the proof of Theorem 1 and assuming that the evaluated input vector has strictly positive components, we may change constraint (11.4) by $\nu_{i} \geq 1 / m x_{i 0}, i=1, \ldots, m$. In this manner, (12) can be rewritten as program $(13)^{3}$.

$$
W A_{I, t}^{P L A}\left(x_{i 0}^{t+1}, y_{0}^{t+1}\right)=\operatorname{Min} \sum_{i=1}^{m} \frac{\left|s_{i}^{-}\right|}{m x_{i 0}^{t+1}}
$$

s.t.

$$
\begin{aligned}
& \sum_{j=1}^{n} \lambda_{j} x_{i j}^{t}+s_{i}^{-}=x_{i 0}^{t+1}, \quad i=1, \ldots, m \\
& \sum_{j=1}^{n} \lambda_{j} y_{j}^{t}=y_{0}^{t+1} \\
& \sum_{i=1}^{m} \nu_{i} x_{i j}^{t}-\mu y_{j}^{t}-d_{j}=0, \quad j=1, \ldots, n \\
& \nu_{i} \geq 1 / m x_{i 0}^{t+1}, \quad i=1, \ldots, m \\
& d_{j} \leq M b_{j}, \quad j=1, \ldots, n \\
& \lambda_{j} \leq M\left(1-b_{j}\right), \quad j=1, \ldots, n \\
& b_{j} \in\{0,1\}, \quad j=1, \ldots, n \\
& \lambda_{j}, \nu_{i}, d_{j} \geq 0, \quad \forall i, j \\
& \mu \geq 0
\end{aligned}
$$

where $d_{j}$ is the slack associated with the inequality $\sum_{i=1}^{m} \nu_{i} x_{i j}^{t}-\mu y_{j}^{t} \geq 0$ and $b_{j}$ is a binary variable that relates $d_{j}$ and $\lambda_{j}$.

The aim of constraints (13.6) and (13.7) is to force that $d_{j}$ and $\lambda_{j}$ do not take strictly positive values simultaneously for every $j=1, \ldots, n$. These expressions involve a big positive $M$, and it is known that it could produce numeric problems of computing in some cases, especially when the value of the big $M$ is a priori difficult to be fixed. To avoid this potential problem, in the computational part of this paper, we have implemented these expressions using a Special Ordered Set (SOS). SOS is a way to specify the number of nonzero solution values among a set of variables without the need of resorting to fixing a big $M$. The optimizers

\footnotetext{
${ }^{3}$ Model (13) assumes the production of just one output under Constant Returns to Scale. In practice, this is not a great limitation since, on the one hand, most applications devoted to input-specific productivity change utilized only one output and, on the other hand, Constant Returns to Scale is the correct assumption for determining productivity regardless of the actual returns to scale (see, e.g., Kapelko et al. 2015a). However, any deviation of these assumptions implies that our approach, based on the models by Aparicio et al. (2007), does not work correctly. Aparicio et al. (2016) have studied in detail least distance models for oriented frameworks, proposing an innovative and general methodology that always correctly performs based upon BiLevel Linear Programming and moving away, therefore, from the well-known Aparicio et al. (2007) approach. Moreover, our model is in line with the original idea of input-specific productivity change that is rooted in the growth accounting literature (cf. Solow 1957). Growth accounting measures the contribution of different production factors (such as capital, labor and materials) to the growth of total output and indirectly computes the change of total factor productivity (or technical progress). It is based on the traditional production function relating the production of a single output to multiple inputs assuming Constant Returns to Scale.
} 
usually achieve it by using special branching strategies. Traditionally, SOS was used with discrete and integer variables, but modern optimizers like CPLEX have also extended it to continuous variables. Thus, the goals marked by constraints (13.6) and (13.7) are guaranteed.

Additionally, program (13) determines the least distance between $x_{i 0}^{t+1}$ and $\partial^{s}\left(L^{t}\left(y_{0}^{t+1}\right)\right)$. However, it cannot be considered a distance function, as for example the directional input distance function because the optimal value of the objective function is always non-negative regardless of whether the assessed unit is inside or outside the reference technology. To define a suitable distance function from model (13), we first need to resort to the Shephard input distance function or the input directional distance function, in order to determine whether $x_{i 0}^{t+1}$ belongs to $L^{t}\left(y_{0}^{t+1}\right)$ or not. In this way, from the optimal value and an optimal solution of (13) we can derive the following additive-type distance function.

$$
D_{I, t}\left(x_{i 0}^{t+1}, y_{0}^{t+1}\right)
$$

$$
=\left\{\begin{array}{cc}
\sum_{i=1}^{m} \frac{\left|s_{i}^{-*}\right|}{m x_{i 0}^{t+1}}=\frac{\left|s_{1}^{-*}\right|}{m x_{10}^{t+1}}+\ldots+\frac{\left|s_{m}^{-*}\right|}{m x_{m 0}^{t+1}}, & \text { if } x_{i 0}^{t+1} \in L^{t}\left(y_{0}^{t+1}\right) . \\
-\sum_{i=1}^{m} \frac{\left|s_{i}^{-*}\right|}{m x_{i 0}^{t+1}}=\left(-\frac{\left|s_{1}^{-*}\right|}{m x_{10}^{t+1}}\right)+\ldots+\left(-\frac{\left|s_{m}^{-*}\right|}{m x_{m 0}^{t+1}}\right), & \text { Otherwise }
\end{array}\right.
$$

Using a different notation, the distance function in (14) may be expressed as $D_{I, t}\left(x_{i 0}^{t+1}, y_{0}^{t+1}\right)=\sum_{i=1}^{m} \delta_{i, t}$ $\left(x_{i 0}^{t+1}, y_{0}^{t+1}\right)$, where $\delta_{i, t}\left(x_{i 0}^{t+1}, y_{0}^{t+1}\right)$ equals $\frac{\left|s_{i}^{-*}\right|}{m x_{i 0}^{t+1}}, \forall i=1, \ldots, m$, or $-\frac{\left|s_{i}^{-*}\right|}{m x_{i 0}^{t+1}}, \forall i=1, \ldots, m$, depending if $x_{i 0}^{t+1} \in L^{t}\left(y_{0}^{t+1}\right)$, or not.

Now, we are able to measure productivity change by defining a Luenberger-type productivity indicator ${ }^{4}$ and decompose it into its input-specific components. The $i$-th productivity change for unit 0 is measured by means of:

$$
\begin{aligned}
& \operatorname{TFPCH}_{i 0}(t, t+1)= \\
& \frac{1}{2}\left[\left(\delta_{i, t}\left(x_{i 0}^{t}, y_{0}^{t}\right)-\delta_{i, t}\left(x_{i 0}^{t+1}, y_{0}^{t+1}\right)\right)\right. \\
& \left.+\left(\delta_{i, t+1}\left(x_{i 0}^{t}, y_{0}^{t}\right)-\delta_{i, t+1}\left(x_{i 0}^{t+1}, y_{0}^{t+1}\right)\right)\right] .
\end{aligned}
$$

This input-specific Luenberger indicator may then be decomposed into the input-specific technical efficiency

\footnotetext{
${ }^{4}$ The Luenberger indicator utilized in this section is not the standard indicator but an input-specific version that depends on $\delta_{i, h}\left(x_{i 0}^{p}, y_{0}^{p}\right)$.
}

change (EFFCH) and the input-specific frontier shift (TECHCH).

$$
\begin{gathered}
\operatorname{EFFCH}_{i 0}(t, t+1)=\delta_{i, t}\left(x_{i 0}^{t}, y_{0}^{t}\right)-\delta_{i, t+1}\left(x_{i 0}^{t+1}, y_{0}^{t+1}\right) \\
\operatorname{TECHCH}_{i 0}(t, t+1)=\frac{1}{2}\left[\left(\delta_{i, t+1}\left(x_{i 0}^{t+1}, y_{0}^{t+1}\right)-\delta_{i, t}\left(x_{i 0}^{t+1}, y_{0}^{t+1}\right)\right)\right. \\
\left.+\left(\delta_{i, t+1}\left(x_{i 0}^{t}, y_{0}^{t}\right)-\delta_{i, t}\left(x_{i 0}^{t}, y_{0}^{t}\right)\right)\right]
\end{gathered}
$$

Finally, we introduce the expressions associated with overall productivity change and its components:

$$
\begin{aligned}
\operatorname{TFPCH}_{0}(t, t+1) & =\sum_{i=1}^{m} \operatorname{TFPCH}_{i 0}(t, t+1), \\
\operatorname{EFFCH}_{0}(t, t+1) & =\sum_{i=1}^{m} \operatorname{EFFCH}_{i 0}(t, t+1), \\
\operatorname{TECHCH}_{0}(t, t+1) & =\sum_{i=1}^{m} \operatorname{TECHCH}_{i 0}(t, t+1) .
\end{aligned}
$$

The following simple illustrative example shows how the new approach based on PLA works. The example dataset presented in Table 1 consists of the three units A, B, and C observed in the periods $t$ and $t+1$.

For illustrative purposes, we compare the results from our approach with the model from Mahlberg and Sahoo (2011) which we consider as traditional. We explain the difference between the outcomes of both models by taking the example of unit $\mathrm{C}$ as presented in Fig. 2 and Fig. 3.

Both figures show the input requirement sets. The input levels are normalized by the output levels meaning that the presented data are equivalent to the inverted partial productivities of the two inputs. The bold solid lines $\mathrm{A}(\mathrm{t})$ to $\mathrm{B}$ (t) and $\mathrm{A}(\mathrm{t}+1)$ to $\mathrm{C}(\mathrm{t}+1)$ correspond to the strongly efficient frontiers in $t$ and $t+1$, respectively. Relative to the frontier in

Table 1 Illustrative example

\begin{tabular}{lccccccc}
\hline & \multicolumn{2}{l}{ Period $t$} & & & \multicolumn{2}{c}{ Period $t+1$} & \\
\cline { 2 - 3 } \cline { 6 - 8 } Unit & $x_{1}$ & $x_{2}$ & $y$ & & $x_{1}$ & $x_{2}$ & $y$ \\
\hline A & 5 & 13 & 12 & 9 & 9 & 22 \\
B & 17 & 15 & 26 & 15 & 14 & 20 \\
C & 16 & 26 & 26 & 8 & 23 & 26 \\
\hline
\end{tabular}




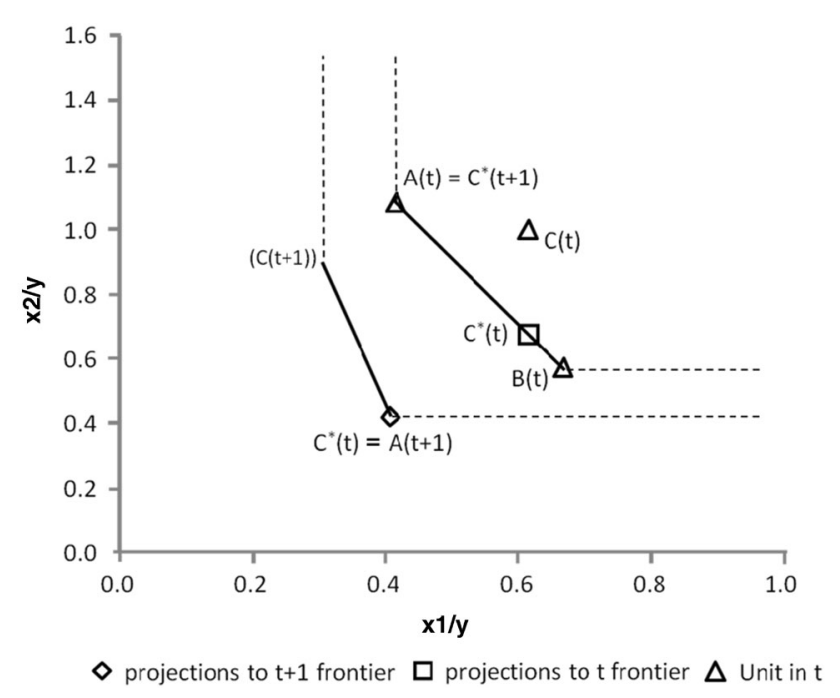

Fig. 2 Projections of the approach by Mahlberg and Sahoo (2011)

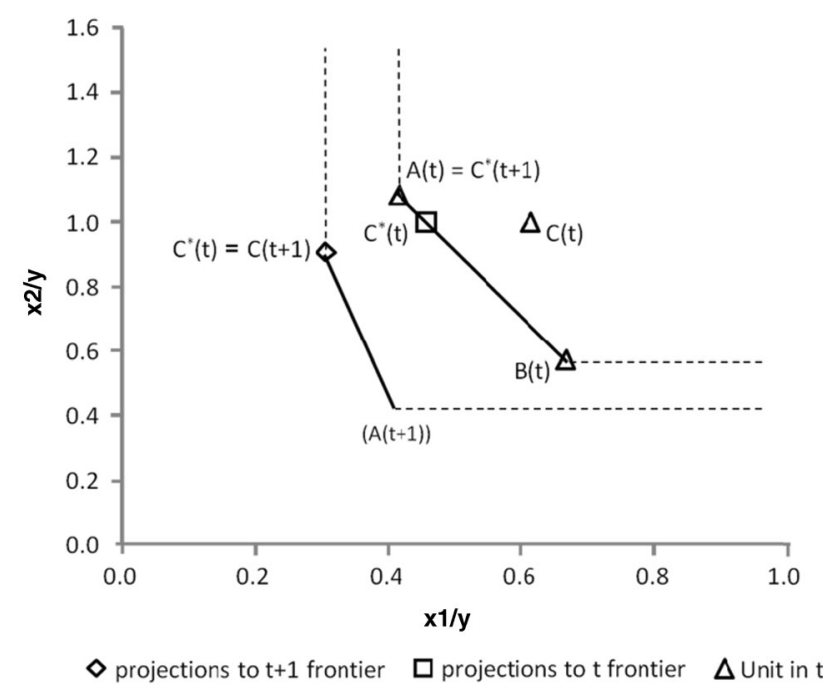

Fig. 3 Projections based on the principle of least action

$t$ unit $C(t)$ is inefficient and unit $C(t+1)$ super-efficient, and relative to frontier in $t+1$ unit $C(t)$ is inefficient and unit $\mathrm{C}(\mathrm{t}+1)$ efficient. Hence, we observe a clear efficiency progress. Moreover, the frontier shifts to the left and downwards indicating a clear technical progress. Finally, unit $\mathrm{C}(\mathrm{t}+1)$ is clearly in the west of and slightly in the south of $\mathrm{C}(\mathrm{t})$. Based on this, we expect productivity gain in terms of both inputs where the gain with respect to input 1 clearly exceeds that with respect to input 2 . For producing one unit of output a much lesser amount of input 1 is used than of input 2 in period 2 compared to period 1.

The traditional approach projects unit $\mathrm{C}(\mathrm{t})$ strictly vertically to the point $\mathrm{C}^{*}(\mathrm{t})$ on the frontier in $\mathrm{t}$ as Fig. 2 shows. Moreover, it combines horizontal and vertical directions and projects unit $\mathrm{C}(\mathrm{t})$ to $\mathrm{A}(\mathrm{t}+1)$ on the frontier in $\mathrm{t}+1$ which is the furthest point. Finally, this approach projects unit
Table 2 Input-specific productivity change for unit $\mathrm{C}$ of the illustrative example dataset

\begin{tabular}{lccc}
\hline & $\begin{array}{l}\text { Efficiency } \\
\text { change }\end{array}$ & $\begin{array}{l}\text { Technical } \\
\text { change }\end{array}$ & $\begin{array}{l}\text { Productivity } \\
\text { change }\end{array}$ \\
\hline $\begin{array}{l}\text { Input-specific productivity change based on Mahlberg and Sahoo } \\
(2011)\end{array}$ & & \\
Input 1 & 0.000 & 0.172 & 0.172 \\
Input 2 & 0.171 & 0.119 & 0.290 \\
Overall & 0.171 & 0.291 & 0.462 \\
Input-specific productivity change based on the Principle of Least \\
Action \\
Input 1 \\
$\begin{array}{l} \\
\text { Input 2 }\end{array}$ \\
Overall & 0.130 & 0.149 & 0.279 \\
\hline
\end{tabular}

$\mathrm{C}(\mathrm{t}+1)$ to $\mathrm{A}(\mathrm{t})$ on the frontier in $\mathrm{t}$ which is the furthest point, again. As opposed to the traditional model, the new approach based on PLA projects unit $\mathrm{C}(\mathrm{t})$ horizontally to the point $C^{*}(t)$ on the frontier in $t$ as Fig. 3 shows. Furthermore, it projects the unit $\mathrm{C}(\mathrm{t})$ to the point $\mathrm{C}(\mathrm{t}+1)$ on the frontier in $t+1$. Lastly, this approach projects $C(t+1)$ to the point $A(t)$ at the frontier in $t$.

Obviously, the projections are quite diverse which results in different scores for productivity change and its components as can be seen in Table 2. The last column shows the productivity change scores. According to the traditional approach, the progress with respect to input 1 is smaller than with respect to input 2 which is contrary to what we expect based on the foregoing discussion. Contrary, the results from the new approach clearly show greater progress in terms of input 1 than in terms of input 2 which is in line with our above discussion and much more plausible. The overall productivity progress is greater according to the traditional approach which might indicate an overestimation. For technical change we observe a similar situation which is reflected by the results in Table 2 .

\section{An empirical application}

In this section, we describe how our model can be used to estimate productivity growth in the manufacturing sector of dairy products in Poland, to illustrate the applicability of our proposed approach. We use our model to estimate drivers of productivity growth in this sector over the 2003-2012 period.

\subsection{The data}

The data used in this study are drawn from the AMADEUS database, which is a dataset containing financial accounts of European companies. The sample includes firms belonging to the dairy processing industry (NACE Rev. 2 code 10.5). 
The dataset used for analysis is obtained by first removing any firms with missing observations and then by removing any outliers. To detect outliers, we follow Simar's (2003) proposal which is based on the application of the order-m efficiencies of Cazals et al. (2002). The final data set is unbalanced and consists of 1134 observations of dairy processing firms in Poland for the 2003-2012 period.

One output and three inputs are distinguished in the computation of input-specific productivity growth. Output is proxied by the firms' revenues taken directly from the AMADEUS database. This variable is deflated to 2003 constant prices using the producer price index for the food manufacturing industry. Inputs consist of employee costs, material costs and fixed assets ${ }^{5}$, extracted directly from the AMADEUS database, and further deflated using the labor cost index in industry, the producer price index for nondurable consumer goods and the producer price index for investment goods, respectively. ${ }^{6}$ All aforementioned price indices used to deflate the inputs and the output are supported by the Eurostat (2014) database. The inputs and output are all measured in millions of Polish Zloty (PLN). Table 3 provides the descriptive statistics of the data used in the application for the studied period (2003-2012).

From Table 3 it can be seen that, on average, among inputs, material costs have the largest values, followed by fixed assets and employee costs. In addition, the standard deviations of variables relative to their respective means are relatively high, indicating that the firms in our sample differ considerably in terms of size. This is especially the case for fixed assets, for which standard deviation is approximately four times larger than the mean.

\subsection{Results}

The computations of input-specific productivity changes and their decomposition are undertaken for firms in the

\footnotetext{
${ }^{5}$ Regarding fixed assets, model (13) may be adapted to short run situations where some inputs cannot be altered by the decision maker and, therefore, must be assumed fixed. To do this, it is enough to remove the respective input slack from the objective function of (13). Nevertheless, in our empirical application, we assume a long run production function, where fixed inputs can be also modified. In fact, in most studies on input-specific efficiency and productivity, fixed inputs are considered as one of the inputs in empirical applications for which efficiency and productivity are calculated (see, e.g., Chang et al. 2012; Skevas and Oude Lansink 2014).

${ }^{6}$ In the related literature on efficiency and productivity in the food manufacturing industry, it is common to use inputs and outputs measured in monetary values as quantity data are often not available (see, e.g., Doucouliagos and Hone 2001; Soboh et al. 2012; Kapelko et al. 2015b, 2016). In our empirical application, we deflated the inputs and the output in order to convert the nominal values to real input and output measures. In this way, we avoided a bias due to inflation and generated implicit quantity indexes as the ratio of the value to price index.
}

Table 3 Descriptive statistics of the data of Polish dairy processing firms, 2003-2012 (million PLN of 2003)

\begin{tabular}{lrrrr}
\hline Variable & Mean & $\begin{array}{l}\text { Standard } \\
\text { deviation }\end{array}$ & Minimum & Maximum \\
\hline Inputs & & & & \\
Employee costs & 7.721 & 11.871 & 0.104 & 79.063 \\
Material costs & 138.790 & 244.815 & 6.268 & 2033.740 \\
Fixed assets & 56.266 & 227.777 & 1.168 & 3220.815 \\
Outputs & & & & \\
Revenues & 173.565 & 306.714 & 6.085 & 2195.317 \\
\hline
\end{tabular}

sample for each pair of two consecutive years in the 2003-2012 period $^{7}$, and then using these results we calculate the arithmetic mean over the entire study period. Table 4 presents these means when both the input-specific Luenberger indicator proposed in this paper and the traditional input-specific Luenberger indicator of Mahlberg and Sahoo (2011) (with directional vector for inputs equal to actual values of inputs) are applied. The second and the third column show efficiency change and technical change, respectively. The last column presents productivity change, which is equal to efficiency change plus technical change. Hence, the values in the last column are the sums of the respective rows. The rows show the input-specific efficiency changes, input-specific technical changes, and inputspecific productivity changes. The values in the bottom row indicate overall efficiency change, technical change and productivity change (i.e., the respective column sums). For productivity changes as well as efficiency changes and technical changes, positive figures indicate progress and negative regress, while a value equal to zero indicates that there has been no effect. The last four rows in Table 4 report the results of the Simar and Zelenyuk (2006) test (denoted further as $\mathrm{S}-\mathrm{Z}$ test) that assesses the differences between indicators computed using both approaches. In addition, Table 5 shows the correlations between both approaches.

Our analysis in Table 4 shows that for both approaches, on average, the overall productivity growth rate is negative, indicating productivity regress for Polish dairy manufacturing firms of $-1.5 \%$ for the traditional approach and $-0.4 \%$ for the new approach. Furthermore, the results for three inputs show that the decline in productivity is attributed to less productive utilization of labor and fixed assets in the case of the traditional approach, and of

\footnotetext{
7 The computation times of the new approach varied between 3 seconds (for 2004/2005) and 12 seconds (for 2010/2011). The computations were undertaken with a PC with an Intel Xeon Dual Core processor of $2.33 \mathrm{GHz}$, with $8.5 \mathrm{~GB}$ of RAM. The optimization software package CPLEX v11.0 was used in computations. Additionally, the code can be downloaded at http://deacode.blogspot.com.es/.
} 
Table 4 Productivity change of three inputs and overall in the Polish dairy processing firms (arithmetic means across periods 2003/ 2004-2011/2012)

\begin{tabular}{lccc}
\hline & $\begin{array}{l}\text { Efficiency } \\
\text { change }\end{array}$ & $\begin{array}{l}\text { Technical } \\
\text { change }\end{array}$ & $\begin{array}{l}\text { Productivity } \\
\text { change }\end{array}$ \\
\hline Input-specific productivity change based on Mahlberg and Sahoo \\
(2011) \\
Employee costs & -0.007 & 0.004 & -0.003 \\
Material costs & 0.000 & 0.000 & 0.000 \\
Fixed assets & 0.001 & -0.013 & -0.012 \\
Overall & -0.006 & -0.009 & -0.015 \\
Input-specific productivity change based on the principle of least \\
action \\
Employee costs & -0.002 & 0.004 & 0.002 \\
Material costs & 0.005 & -0.009 & -0.004 \\
Fixed assets & -0.003 & 0.001 & -0.002 \\
Overall & 0.000 & -0.004 & -0.004 \\
S-Z statistics & & & \\
Employee costs & $122.685^{* * *}$ & $78.811^{* * *}$ & $57.626 * * *$ \\
Material costs & $190.516^{* * *}$ & $192.642^{* * *}$ & $152.802 * * *$ \\
Fixed assets & $101.177^{* * *}$ & $140.586^{* * *}$ & $94.595^{* * *}$ \\
Overall & $34.991 * * *$ & $40.735^{* * *}$ & $49.573 * * *$ \\
\hline
\end{tabular}

***denotes significant differences between indicators based on Mahlberg and Sahoo (2011) and on the Principle of Least Action at the critical $1 \%$ level

materials and fixed assets for the new approach. The results point also to positive input-specific productivity change for labor as revealed by the new approach and no change in productivity for materials as indicated by the traditional approach.

Table 4 shows also that according to both approaches, on average, the main driver of the decline in overall productivity is an overall technical regress of Polish dairy firms that amounts to $-0.4 \%$ in the case of the new approach and to $-0.9 \%$ as revealed by the traditional approach. Therefore, the performance of the best performers deteriorate, meaning that the production frontier shifts downwards. This deterioration comes from a clear technical regress in the use of material in the case of the new approach, and in the use of fixed assets in the case of the traditional method. In terms of labor employment, both approaches report technical progress. In addition, the traditional approach finds no technical change for materials, and the new approach reports slight technical progress for fixed assets. Interestingly, in the case of traditional approach we find, on average, an overall efficiency decrease of $-0.6 \%$, showing that the underperformers do not get closer to the best performers, while new approach indicates no change in efficiency. The employment of labor is responsible for overall efficiency decrease in the traditional approach. But the new approach reveals that labor and fixed assets contributed negatively to overall efficiency, while materials did so positively.

Overall, the results in Table 4 suggest that the magnitude of change in indicators regarding all three inputs and overall is very small. It also shows that there are significant differences in results reported in both approaches as indicated by the S-Z test. Moreover, while the average results of overall indicators tell a similar story in both the traditional and new approaches, the conclusions regarding the contributions of individual inputs differ considerably between both. It is further confirmed by the results of correlations in Table 5 that highlight very low correlations between inputspecific productivity change, efficiency change and technical change of the two models used, but much larger between overall indicators. This discrepancy of findings in the two approaches arise from, among others: (1) the differences in the philosophy followed to project units onto the frontier (closest vs. furthest targets), and (2) the monotonicity with respect to the projection of the assessed unit (the new approach does not seek that the projection point dominates the evaluated unit in the sense of Pareto).

In order to provide some interpretations of the findings from the context of the dairy manufacturing industry in Poland, we next analyze the input-specific and overall productivity growth and its decomposition for the new approach for different time periods. Figure 4 shows the development of indicators for each pair of consecutive years in the 2003-2012 period.

The figure shows that the magnitudes of changes of indicators are similar for each input across all periods. It also demonstrates with regard to overall indicators that the beginning of the period analyzed (2003-2007) is characterized by technical progress and productivity growth, despite efficiency decline, while the second part of the period analyzed (2008-2012) shows the general trends of negative technical change and productivity change, and positive efficiency change. ${ }^{8}$ It is worth noting that similar findings regarding productivity change are reported, e.g., in Jansik et al. (2014).

The beginning of this period is related to the Polish preaccession and accession to the European Union (EU). After meeting the initial EU requirements, the sector experienced substantial growth resulting from a broad stream of subsidies, growth in exports, and inflow of foreign investments as a significant source of innovations (Polish Information and Foreign Investment Agency 2013). Therefore, it is not surprising that dairy manufacturing firms in Poland made advances regarding technology, as confirmed by our results on technical progress. However, our findings for this period also indicate the growth of the gap between efficient and

\footnotetext{
${ }^{8}$ In fact, when we compute average values of indicators for these two sub-periods, we would find these trends exactly as described.
} 
Table 5 Correlations between indicators (across all periods 2003/2004-2011/2012)
Mahlberg and Sahoo (2011)

Principle of least action

Efficiency change

Employee costs

Mahlberg and Sahoo (2011)

1.000

0.199

Principle of Least Action

0.199

1.000

Material costs

Mahlberg and Sahoo (2011)

1.000

0.112

Principle of Least Action

0.112

1.000

Fixed assets

Mahlberg and Sahoo (2011)

1.000

0.284

Principle of Least Action

0.284

1.000

Overall

Mahlberg and Sahoo (2011)

1.000

0.589

Principle of Least Action

0.589

1.000

Technical change

Employee costs

Mahlberg and Sahoo (2011)

1.000

0.493

Principle of Least Action

0.493

1.000

Material costs

Mahlberg and Sahoo (2011)

1.000

0.397

Principle of Least Action

0.397

1.000

Fixed assets

Mahlberg and Sahoo (2011)

1.000

0.316

Principle of Least Action

Overall

Mahlberg and Sahoo (2011)

Principle of Least Action

0.316

1.000

1.000

0.622

0.622

1.000

Productivity change

Employee costs

Mahlberg and Sahoo (2011)

1.000

0.460

Principle of Least Action

Material costs

Mahlberg and Sahoo (2011)

0.460

1.000

Principle of Least Action

Fixed assets

Mahlberg and Sahoo (2011)

Principle of Least Action

Overall

Mahlberg and Sahoo (2011)

1.000

0.404

0.404

1.000

$\begin{array}{ll}1.000 & 0.461\end{array}$

$0.461 \quad 1.000$

Principle of Least Action $\begin{array}{ll}1.000 & 0.793\end{array}$

0.793
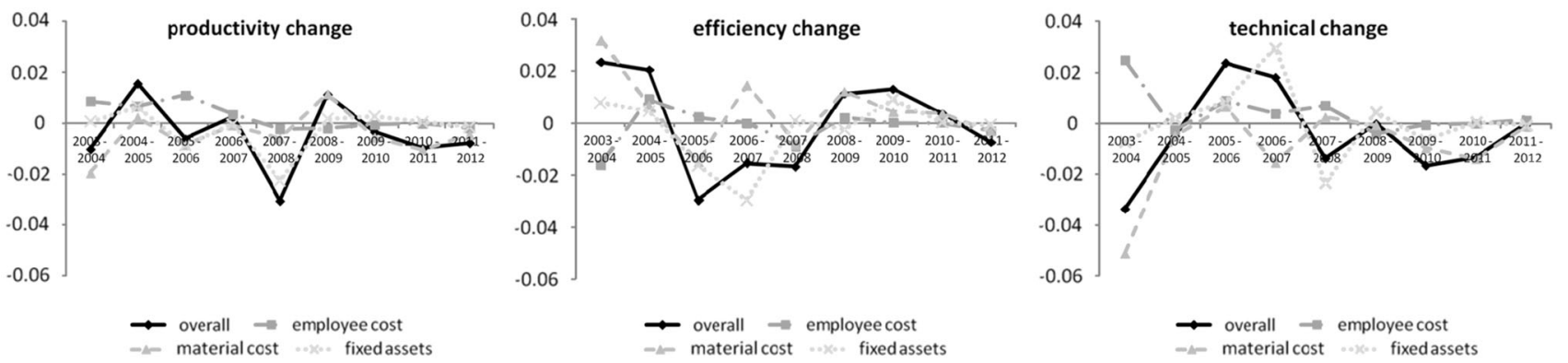

Fig. 4 Evolution of productivity change of three inputs and overall in the Polish dairy processing firms based on the Principle of Least Action, for consecutive periods 2003/2004-2011/2012 
inefficient firms as revealed by negative efficiency change. This could indicate that the technical efficiency change of most firms is slower than that of the frontier technology advancement, that is, few dairy firms in our sample were innovators, while many other firms failed to adapt to technological improvements that has shown as efficiency decrease.

The findings for the second period covered in this study can reflect the negative impact of the volatility of prices experienced by the dairy manufacturing sector from 2008 till the end of 2010, when prices and producers' incomes decreased (European Commission 2012), as well as the influence of the 2008 economic crisis. Although the sector is known for being fairly insensitive to business fluctuations, still the slight slowdown of production and decreased turnover was observed for its constituting firms due to economic crisis (Polish Information and Foreign Investment Agency 2013). In addition, this period is characterized by a certain switch in the demand towards ecofoods and prohealth foods observed in Poland (Wrzesińska-Kowal and Drabarczyk 2014). In particular, this last change could cause the situations of some productive options (technologies) being no longer available for firms to exploit, which could produce the results of technical regress observed in this study ${ }^{9}$. We can expect that when dairy firms adjust to new realities of consumer demand and make investments in new technologies, technological progress should occur in future periods. At the same time, however, our results for this period show efficiency increase (with the exception of 2011/2012), therefore it is possible that the volatility of this period has worked as a disciplining factor for firms that allocated resources more efficiently and adjusted the usage of inputs quickly enough. Finally, the decrease of efficiency in 2011/2012 could be related to the decrease in the consumption of food products along with milk and dairy products that was observed in 2011 and 2012 in Poland (Polish Central Statistical Office 2013; Drożdż et al. 2014).

\section{Conclusions}

This study introduces a new input-oriented weighted additive model for estimating technical inefficiency based on the Principle of Least Action, which is intimately related to the notion of least distance. In addition, the model determines strongly efficient targets. Using this model we develop a Luenberger-type indicator of input-specific productivity change and its decomposition into input-specific efficiency

\footnotetext{
${ }^{9}$ Recent literature questions the results of technical regress found in DEA studies (see, e.g., Diewert and Fox 2016) and proposes the methods to reveal "true" findings. However, the development or application of such methods is out of the scope of this paper.
}

change and input-specific technical change. The proposed indicator has two advantages over existing input-specific productivity measures. First, our model projects inefficient firms to the strongly efficient frontier and therefore estimates Pareto-Koopmans efficiency. Second, our model suggests directions of efficiency and productivity improvements that may be implemented within an organization with least effort.

We apply the new approach to data for Polish dairy processing firms for the 2003-2012 period, and compare the results with the existing input-specific productivity change indicator. The study distinguishes three groups of inputs, namely employment costs, material costs, and fixed assets, and takes revenue as the only output. Our analysis reveals that this sector went through a period of overall productivity regress during the last decade, which was mainly caused by overall technical regress. Nevertheless, the changes observed are relatively low. While both the new approach and the existing approach show similar findings regarding overall productivity change and its components, considerable differences are found regarding contributions of specific inputs towards overall changes.

Based on these findings, the advantages of our proposed method are obvious. Our approach provides insights about the sources of productivity decline from the individual inputs that cannot be offered by standard productivity measures that capture productivity change for all inputs simultaneously. It makes information about the potentials for input-specific reduction available. In this way, it provides concrete hints to decision-makers on how to improve competitiveness with least effort. Moreover, our approach incorporates slacks that are not taken into account in standard productivity measures of all inputs simultaneously, and by projecting towards the strongly efficient frontier, it allows for firms under evaluation to be compared with the best firms.

Currently, the model developed in this study is restricted to one output and Constant Returns to Scale. Future research efforts should focus on the development of a model without these limitations based on Bi-level Linear Programming (see Aparicio et al. 2016). In the first case, it will allow us to deal with multiple outputs and multiple inputs in the input-oriented context while, in the second case, the application of this kind of technique will permit us to decompose the efficiency change into pure efficiency change and scale efficiency change. Furthermore, the application of the model developed in the paper to other real-life datasets, for example to model eco-efficiency and inclusion of undesirable outputs, is another interesting line of future research.

Acknowledgements We would like to express our gratitude to the editor and two anonymous referees for their helpful comments. 
Magdalena Kapelko would like to acknowledge the funding by the National Science Centre in Poland, decision number DEC-2013/11/D/ HS4/00252. Juan Aparicio would like to express his gratitude to the Spanish Ministry for Economy and Competitiveness for supporting this research under grant MTM2013-43903-P. We also thank the comments of participants at the 14th European Workshop on Efficiency and Productivity Analysis (EWEPA 2015) in Helsinki and the OR2015 International Conference on Operations Research in Vienna. The usual disclaimer applies.

\section{Compliance with ethical standards}

Conflict of interest The authors declare that they have no conflict of interest.

\section{References}

Ando K, Kai A, Maeda Y, Sekitani K (2012) Least distance based inefficiency measures on the Pareto-efficient frontier in DEA. J Oper Res Soc Jap 55:73-91

Aparicio J, Ruiz JL, Sirvent I (2007) Closest targets and minimum distance to the Pareto-efficient frontier in DEA. J Prod Anal 28:209-218

Aparicio J, Pastor JT (2013) A well-defined efficiency measure for dealing with closest targets in DEA. Appl Math Comput 219:9142-9154

Aparicio J, Pastor JT (2014) Closest targets and strong monotonicity on the strongly efficient frontier in DEA. Omega 44:51-57

Aparicio J, Mahlberg B, Pastor JT, Sahoo BK (2014) Decomposing technical inefficiency using the principle of least action. Eur $\mathbf{J}$ Oper Res 239:776-785

Aparicio J, Cordero JM, Pastor JT (2016) The determination of the least distance to the strongly efficient frontier in Data Envelopment Analysis oriented models: modelling and computational aspects. Omega, MPRA Paper No. 72630 (see sector in Poland). doi:10.1016/j.omega.2016.09.008

Banker RD, Charnes A, Cooper WW (1984) Some models for estimating technical and scale inefficiencies in data envelopment analysis. Manage Sci 30:1078-1092

Briec W (1998) Hölder distance function and measurement of technical efficiency. J Prod Anal 11:111-131

Briec W, Kerstens K (2009) Infeasibility and directional distance functions with application of determinateness of the Luenberger productivity indicator. J Optimiz Theory App 141:55-73

Cazals C, Florens J, Simar L (2002) Nonparametric frontier estimation: a robust approach. J Econom 106:1-25

Chambers RG, Färe R, Grosskopf S (1996) Productivity growth in APEC countries. Pac Econ Rev 1:181-190

Chambers RG, Chung Y, Färe R (1998) Profit, directional distance functions, and Nerlovian efficiency. J Optimiz Theory App 98:351-364

Chang T-P, Hu J-L, Chou RY, Sun L (2012) The sources of bank productivity growth in China during 2002-2009: a disaggregation view. J Bank Financ 36:1997-2006

Charnes A, Cooper WW, Rhodes E (1978) Measuring the efficiency of decision making units. Eur J Oper Res 2:429-444

Coelli T (1998) A multi-stage methodology for the solution of orientated DEA models. Oper Res Lett 23:143-149

Cook WD, Seiford LM (2009) Data envelopment analysis (DEA)-30 years on. Eur J Oper Res 192:1-17

Cooper WW, Park KS, Pastor JT (1999) RAM: a range adjusted measure of inefficiency for use with additive models, and relations to others models and measures in DEA. J Prod Anal $11: 5-42$
Diewert WE, Fox KJ (2016) A decomposition of U.S. business sector TFP growth into technical progress and cost efficiency components. Working paper. Available at: http://econ.sites.olt.ubc.ca/files/2016/ 06/pdf_paper_erwin-diewert-16-04DecompUSBusinessetc.pdf

Doucouliagos H, Hone P (2001) The efficiency of the Australian dairy processing industry. Aust J Agr Resour Ec 44:423-438

Drożdż J, Mroczek R, Tereszczuk M, Urban R (2014) Polish food industry in 2008-2013. Institute of Agricultural and Food Economics - National Research Institute, Warsaw

D'Haese M, Speelman S, Alary V, Tillard E, D'Haese L (2009) Efficiency in milk production on Reunion Island: dealing with land scarcity. J Dairy Sci 92:3676-3683

European Commission (2012). Evolution of the market situation and the consequent conditions for smoothly phasing out the milk quota system-second "soft landing" report. Report from the European Commission to the European Parliament and the Council. Brussels, 10.12.2012, COM(2012) 741

Eurostat (2014). Short-term business statistics. http://ec.europa.eu/ eurostat/web/short-term-business-statistics/data/database. Accessed 15 Sept 2014

Färe R, Grosskopf S, Lovell CAK (1985) The measurement of efficiency of production. Kluwer Nijhof Publishing, Norwell, MA

Färe R, Grosskopf S, Lovell CAK (1994) Production frontiers. Cambridge University Press, Cambridge

Fukuyama H, Weber WL (2009) A directional slacks-based measure of technical inefficiency. Socioecon Plann Sci 43:274-287

Fukuyama H, Maeda Y, Sekitani K, Shi J (2014a) Input-output substitutability and strongly monotonic p-norm least-distance DEA measures. Eur J Oper Res 237:997-1007

Fukuyama H, Masaki H, Sekitani K, Shi J (2014b) Distance optimization approach to ratio-form efficiency measures in data envelopment analysis. J Prod Anal 42:175-186

Gonzalez E, Alvarez A (2001) From efficiency measurement to efficiency improvement: the choice of a relevant benchmark. Eur $\mathbf{J}$ Oper Res 133:512-520

Jansik C, Irz X, Kuosmanen N (2014) Competitiveness of Northern European dairy chains. MTT Economic Research, Agrifood Research Finland, Helsinki

Joro T, Korhonen P, Walleniuss J (1998) Structural comparison of data envelopment analysis and multiple objective linear programming. Manage Sci 44:962-970

Kapelko M, Horta IM, Camanho AS, Oude Lansink A (2015a) Measurement of input-specific productivity growth with an application to the construction industry in Spain and Portugal. Int J Prod Econ 166:64-71

Kapelko M, Oude Lansink A, Stefanou SE (2015b) Effect of food regulation on the Spanish food processing industry: a dynamic productivity analysis. PLoS ONE 10(6):e0128217. doi:10.1371/ journal.pone. 0128217

Kapelko M, Oude Lansink A, Stefanou SE (2016) Investment age and dynamic productivity growth in the Spanish food processing industry. Am J Agric Econ 98:946-961

Koopmans TC (1951) An analysis of production as an efficient combination of activities. In: Koopmans TC (ed) Activity analysis of production and allocation. Wiley, New York

Lovell CAK, Pastor JT (1995) Units invariant and translation invariant DEA models. Oper Res Lett 18:147-151

Luptacik M, Mahlberg B (2016) Productivity change in a multisectoral economic system. Econ Syst Res 28:344-361

Mahlberg B, Sahoo BK (2011) Radial and non-radial decomposition of Luenberger productivity indicator with an illustrative application. Int J Prod Econ 131:721-726

Mahlberg B, Luptacik M, Sahoo BK (2011) Examining the drivers of total factor productivity change with a ("an") illustrative example of 14 EU countries. Ecol Econ 72:60-69 
Mahlberg B, Luptacik M (2014) Eco-efficiency and eco-productivity change over time in a multisectoral economic system. Eur J Oper Res 234:885-897

Oude Lansink A, Silva E (2003) $\mathrm{CO}_{2}$ and energy efficiency of different heating technologies in the Dutch glasshouse industry. Environ Resour Econ 24:395-407

Oude Lansink A, Ondersteijn Ch (2006) Energy productivity growth in the Dutch greenhouse industry. Am J Agric Econ 88: $124-132$

Pastor JT, Ruiz JL, Sirvent I (1999) An enhanced DEA Russell graph efficiency measure. Eur J Oper Res 115:596-607

Pastor JT, Aparicio J (2010) A note on "A directional slacks-based measure of technical inefficiency". Socioecon Plann Sci 44:174-175

Polish Information and Foreign Investment Agency (2013). Food sector in Poland. Available at: http://www.paiz.gov.pl/files/?id_ plik $=21682$

Polish Central Statistical Office (2013). Statistical yearbook of agriculture 2013. Available at: http://stat.gov.pl/download/gfx/ portalinformacyjny/en/defaultaktualnosci/3328/6/8/5/sy_statistical_ yearbook_agriculture_2013.pdf
Portela MCAS, Castro P, Thanassoulis E (2003) Finding closest targets in non-oriented DEA models: the case of convex and nonconvex technologies. J Prod Anal 19:251-269

Simar L (2003) Detecting outliers in frontier models: a simple approach. J Prod Anal 20:391-424

Simar L, Zelenyuk V (2006) On testing equality of distributions of technical efficiency scores. Economet Rev 25(4):497-522

Skevas T, Oude Lansink A (2014) Reducing pesticide use and pesticide impact by productivity growth: the case of Dutch arable farming. J Agric Econ 65:191-211

Soboh R, Oude Lansink A, Van Dijk G (2012) Efficiency of cooperatives and investor owned firms revisited. J Agric Econ 63:142-157

Solow R (1957) Technical change and the aggregate production function. Rev Econ Stat 39:312-320

Tone K (2001) A slacks-based measure of efficiency in data envelopment analysis. Eur J Oper Res 130:498-509

Wrzesińska-Kowal J, Drabarczyk K (2014) Food production in Poland, compared to selected European Union Member states. Scientific Journal of Warsaw University of Life Sciences 14:205-214 